and same year of publication, is unconnected and quite orthodox. It is written by a physician and recommends a low-fat regimen high in complex carbohydrate and gentle exercise.

The Prudent diet $^{14}$ is by now a classic that originated in the Anti-Coronary Club in New York City in 1956. A balanced diet that reduces saturated fats and partially replaces them with polyunsaturated oils, it may be used for weight reduction because fats provide $3.7 \mathrm{MJ}(900 \mathrm{kcal}) / 100 \mathrm{~g}$ compared with under $1.7 \mathrm{MJ}(400 \mathrm{kcal}) / 100 \mathrm{~g}$ for pure starch and less than this for starchy foods, which contain water as well-for example, bread 1.0 MJ (233 kcal) and boiled potatoes $0.3 \mathrm{MJ}(80 \mathrm{kcal}) / 100 \mathrm{~g}$. Carbohydrate counters have largely been replaced by energy counters as the dieter's ready reckoner that concentrates on the most useful single set of numbers. But recently books of fat units ${ }^{15}$ are to be found in the newsagents, reflecting nutritional opinion that the first component to cut in a reducing diet should be the fat.

Most pop reducing diets originated in the United States and spread across the world. The F-plan diet $^{16}$ originates in Britain, where it is already a best seller. It prescribes a highfibre intake (hence F-plan) from cereals and fruit, an allowance of skimmed milk, and selection from a set of recipes which are low in fat and use a lot of legumes. For a change the foods have a British ring: damsons, blackberries, runner beans, and Hovis.

Most medical nutritionists have by now abandoned (if they ever supported) diets for weight reduction that are disproportionately low in carbohydrate, and the same trend can be seen among pop diets. There are maverick exceptions, but several of the recently published ones-such as the F-plan, the Beverly Hills medical diet, and the Pritikin regimenconcentrate on removing fat and adding dietary fibre. Even Dr Atkins has moved in this direction. On the whole these diets are healthier and closer to orthodox opinion than their counterparts were 10 years ago. But some of the unphysiological regimens from the 1960s and early 1970s are still on sale in the bookshops; they should be cleared out for new stock.

\section{A STEWART TRUSWELI}

Boden Professor of Human Nutrition,

Sydney University,

New South Wales 2006,

Australia

1 Yudkin J. This slimming business. Harmondsworth: Penguin, 1962.

2 Atkins RC. Dr Atkins' diet revolution. New York: Bantam, 1973.

${ }^{3}$ Kouwenhoven T, Drijver A. Een onderzoek naar het effect van twee typen vermageringsdieten. Voeding $1973 ; 34: 180-215$.

4 Council on Foods and Nutrition. A critique of low-carbohydrate ketogenic weight reduction regimes: a review of Dr Atkins' diet revolution. FAMA 1973;224:1415-9.

' Atkins RC. Dr Atkins' nutrition breakthrough. How to treat your medical condition without drugs. New York: Bantam, 1981

- Stillman IM, Baker SS. The doctor's quick weight loss diet. London: Pan Books, 1970.

7 Stillman IM, Baker SS. Dr Stillman's fourteen-day shape-up program. New York: Delacorte Press, 1974.

- Tarnower H, Baker SS. The complete Scarsdale medical diet. New York: Bantam, 1978.

- Pritikin N, McGrady PM Jr. The Pritikin program for diet and exercise. New York: Grosset and Dunlap, 1979.

10 US Congress Senate Select Committee on Nutrition and Human Needs. Dietary goals for the United States. 2nd ed. Washington DC: US Government Printing Office, 1977.

11 Mazel J. The Beverly Hills diet. London: Sidgwick and Jackson, 1982.

12 Mirkin GB, Shore RN. The Beverly Hills diet: dangers of the newest weight loss fad. $7 A M A 1981 ; 246: 2235-7$.

13 Fox A. The Beverly Hills medical diet. New York: Bantam, 1982.

14 Bennett I, Simon M. The prudent diet. Toronto: Bantam, 1974.

15 Slimming Magazine's dieting revolution. New even easier guide to the super successful low-fat diet. London: Slimming Magazine, 1981.

${ }^{16}$ Eyton F. The F-plan. Harmondsworth: Penguin, 1982.
Antacids for duodenal ulcer?

The past 20 years has seen the introduction of a series of $\widehat{C}$ drugs which are potent inducers of ulcer healing. Do antacids now have any place in treatment? In Britain they have mainiy been used in modest doses as symptomatic remedies, whereas \& the American practice has been to use high doses to try to $\mathrm{m}$ promote ulcer healing. Are these differences in prescribing pattern justified ? Two recent publications (largely overlapping $\stackrel{\vec{\rho}}{\stackrel{\vec{P}}{+}}$ in content) attest to the continuing interest in antacids ${ }^{12}$ and $\bar{C}$ contain useful reviews of current data.

High doses of magnesium-aluminium antacids were clearly $\frac{\bar{\omega}}{\bar{D}}$ shown to promote healing of duodenal ulcers in a study in the $\stackrel{\mathbb{Q}}{\unrhd}$ United States reported five years ago. ${ }^{3}$ The findings in that study supplied a possible reason for the apparently higher $\overrightarrow{0}$ natural healing rate of duodenal ulcer in the United States $\overrightarrow{\vec{H}}$ than in Britain, though it seemed likely that only an enthusiasm $\vec{\sigma}$ bordering on the obsessional would make people take the regimen needed- $30 \mathrm{ml}$ seven times daily of a magnesiumaluminium antacid providing $1008 \mathrm{mmol}$ of neutralising $\underset{\mathrm{N}}{\mathrm{N}}$ capacity. If there were advantages over $\mathrm{H}_{2}$-antagonist treatment they did not lie in convenience, or in cost, which was at least as high, or in freedom from short-term adverse effects-many takers of antacids suffering from troublesome $N$ diarrhoea-or in reduced relapse rates later. ${ }^{4}$

Since then antacids in doses ranging down to 280 and $200 \mathrm{mmol}$ daily ${ }^{6}$ have been shown to promote healing. $Y$ Direct comparison based on the overall neutralising power $Z$ of antacids between results obtained in different places and $\overleftarrow{\Phi}$ with different antacids may be dangerous, but the apparent $\overline{0}$ value of relatively low-dose antacid treatment (which has little effect on intragastric $\mathrm{pH}$ ) is surprising. So far there have $\vec{\varphi}$ been no comparable studies conducted in Britain.

Attempts to show that antacid treatment gives relief from symptoms have generally failed. In the United States a carboxymethylcellulose placebo proved as useful as a potent antacid in relieving symptoms, ${ }^{7}$ a finding in agreement with much other data. In one Scandinavian study ${ }^{5}$ low doses $\stackrel{\mathbb{Q}}{\varrho}$ (280 mmol daily) of antacids were found to promote ulcer $\overrightarrow{\overrightarrow{0}}$ healing but to have only relatively weak symptomatic effects. 3 Although radically different findings can be obtained between sets of data, even within those obtained in two places in a single study, ${ }^{8}$ it seems unlikely, taken overall, that failure to show that antacids will relieve symptoms simply stems from methodological difficulties. Quite why antacids should not $\frac{0}{3}$ give simple symptomatic relief if they will promote ulcer healing is hard to understand.

At first sight the evidence is such as to persuade the physician to abandon the use of antacids in treating symptoms but to prescribe them enthusiastically in trying to heal ulcers. If this were done, however, what substitute could be found $\frac{D}{0}$ to manage symptoms? Antacids in ordinary small doses are cheap and safe; and whether they relieve symptoms or whether $N$ they act simply as placebos may not be of critical importance $\omega$ provided that they satisfy patients, which in most instances they seem to do. In contrast, histamine $\mathrm{H}_{2}$-antagonists provide excellent symptomatic relief and, whatever clinicians may $\stackrel{\mathbb{\Phi}}{\rightarrow}$ wish, are often used as "on-demand" treatment for short periods by patients who have quantities left over in drawers 0 and bathroom cupboards. So far the safety record of $\mathrm{H}_{2}-\stackrel{\mathbb{Q}}{\square}$ antagonists has proved remarkably good, and such self- $\stackrel{\mathbb{Q}}{\varrho}$ treatment seems unlikely to do any harm. Nevertheless, the rational policy is to reserve $\mathrm{H}_{2}$-antagonists for use in a 8 coherent planned manner where symptoms prove resistant음 to simple, time-honoured remedies. 
If antacids are used then some basic facts need to be remembered. Not only sodium bicarbonate but also magnesium trisilicate mixture and the proprietary compound Gaviscon contain large amounts of sodium-which could precipitate heart failure in predisposed patients. Calcium salts, at least in large doses, can cause hypercalcaemia, and, as calcium ions stimulate release of gastrin, can cause rebound hypersecretion. Magnesium and aluminium salts often bind other drugs, reducing the rate and extent of absorption of cimetidine, digoxin, indomethacin, and levodopa among others, ${ }^{9}$ and in large doses used intensively they can bind phosphate, precipitating osteomalacia.

Given in modest doses magnesium-aluminium antacids remain safe, cheap adjuncts to the treatment of duodenal ulcer, even if in the long term they have little effect on the behaviour of the disease.

Professor of Therapeutics,

M J S LANGMAN

City Hospital,

Nottingham NG5 1PB

${ }^{1}$ Forssell $\mathrm{H}$, Walan A, eds. Symposium on antacids. Scand $\mathcal{F}$ Gastroenterol $1982 ; 17$, suppl $75: 1-122$.

${ }^{2}$ Halter F, ed. Antacids in the 'eighties. Munich: Urban and Schwarzenberg, 1982.

${ }^{3}$ Peterson WL, Sturdevant RAL, Frankl HD, et al. Healing of duodenal ulcer with an antacid regime. $N$ Engl f Med 1977;297:341-5.

4 Centre for Ulcer Research and Education. Is duodenal ulcer recurrence more common after cimetidine treatment? Gastroenterology 1980;78: A 1152 .

${ }^{5}$ Berstad A. Antacid therapy of duodenal ulcer. Effects of smaller doses. Scand 7 Gastroenterol 1982;17, suppl 75:97-9.

${ }^{6}$ Lam SK, Lam KC, Lai CL, Yeung CK, Yam LYC, Wong WS. Treatment of duodenal ulcer with antacid and sulpiride. A double-blind controlled study. Gastroenterology 1979;76:315-22.

${ }^{7}$ Sturdevant RAL, Isenberg JI, Secrist D, Ansfield J. Antacid and placebo produced similar pain relief in duodenal ulcer patients. Gastroenterology $1977 ; 72: 1-5$.

${ }^{8}$ Littman A, Welch R, Fruin RC, Aronson AR. Controlled trials of aluminum hydroxide gels for peptic ulcer. Gastroenterology 1977;73: 6-10

${ }^{9}$ Henry DA, Langman MJS. Adverse effects of anti-ulcer drugs. Drugs $1981 ; 21: 444-59$

\section{Hazards of lumbar puncture}

As more non-invasive techniques have become available to supplement the clinical management of patients with neurological disorders older techniques should be reappraised. Though lumbar puncture was introduced by Quincke in 1891, the cellular and chemical abnormalities and the changes in hydrodynamics were fully documented only in 1937 by Merritt and Fremont-Smith in their classical monograph. ${ }^{2}$

In many diseases the "routine" lumbar puncture of old is now superfluous. It is seldom indicated in strokes, since computed tomography will show infarction, haematomas, angiomas, and tumours which may mimic stroke. In suspected compression of the cord an elective myelogram is preferred and has rendered Queckenstedt's test obsolete, except in those hospitals without access to adequate neuroradiology. It is contraindicated in suspected cerebral tumour, abscess, and subdural haematoma.

The routine and generally safe practice of lumbar puncture in cases of suspected spontaneous subarachnoid haemorrhage should also be reassessed. It provides an accurate index of bleeding into the subarachnoid space in all but the exceptional patient in whom the puncture is performed within the first four hours, at which time the blood may have failed to reach the lumbar sac. Computed tomography will show intracranial bleeding and localise the lesion in many cases. The frequency of positive findings varies between $50 \%$ and $100 \%$ in different series. ${ }^{3-6}$ In a recent survey of 74 cases of proved subarachnoid haemorrhage seven patients showed a dramatic deterioration in conscious level and neurological state after lumbar puncture, and four subsequently died, three showing evidence of cerebral dislocation and tentorial or tonsillar coning. They had all had a lumbar puncture within 12 hours of the event, none had had a computed tomographic scan. In this series computed tomography was performed in 64 cases. Where an aneurysm or angioma was present unenhanced computed tomography showed blood in 59 patients examined within three days. Thus there are rare instances of negative scans in patients with definite intracranial haemorrhage. Nevertheless, those who deteriorated dramatically after lumbar puncture were shown to have haematomas causing coning. In most instances of suspected intracranial haemorrhage computed tomography should be the primary investigation. In those patients in whom a haematoma is not shown and in whom there is no hydrocephalus and no bleeding into the ventricles or basal cisterns, it is safe to do a lumbar puncture. Lumbar puncture is especially important to exclude pyogenic meningitis, which may simulate acute subarachnoid bleeding. Lumbar puncture is contraindicated in a patient with hemiplegia or one who is stuporose or comatose, for these signs suggest the presence of a haematoma with a risk of coning.

Lumbar puncture remains a necessary tool for three main indications. Firstly, to obtain information about the cellular, chemical, microbiological, and pressure changes in many neurological diseases. It is, for example, helpful in the Guillain-Barré syndrome and multiple sclerosis, and is essential in the diagnosis of bacterial, fungal, or viral meningitis. Secondly, it is a necessary route for the injection of radio-opaque media, radioactive agents, and air for the diagnosis of certain cranial and spinal lesions. Thirdly, it remains a route for treatment-for example, antibiotics and antitumour drugs.

The perennial problem of lumbar puncture headache ${ }^{78}$ has recently been reviewed. ${ }^{9}$ The headache is generally attributed to leakage of the cerebrospinal fluid through the hole in the dura, which leads to intracranial hypotension with traction on pain-sensitive nerve endings in the dura and intracranial vessels. If a small needle is used and puncture is performed with the needle bevel in the vertical plane of the dural fibres lumbar puncture headache may be reduced. Epidural blood patching may be followed by complications and is not recommended for routine use for prevention of headache. ${ }^{9}$ The routine of laying the patient flat for 24 hours after puncture is still widely practised, yet anecdotal experience of venereologists performing lumbar puncture in ambulant outpatients suggested that this was not necessary.

Two recent studies ${ }^{1011}$ have suggested that the incidence of headache may be reduced by tilting the patient head down, thereby reducing the cerebrospinal fluid pressure in the lumbar sac and decreasing the amount of cerebrospinal leakage. Nevertheless, Hilton-Jones and his colleagues ${ }^{9}$ randomly allocated 76 inpatients in whom lumbar puncture was performed for diagnosis into four groups: those treated tilted and supine, tilted and prone, horizontal and supine, or horizontal and prone for four hours after the procedure, after which they were allowed to get up. No significant difference in the incidence of headache was found among the four groups, though the lowest incidence $(23 \%)$ was in those treated horizontal and supine. These findings parallel the results of another investigation, ${ }^{12}$ which showed no beneficial effect of 24 hours' bed rest after lumbar puncture. Although these 